\title{
INVESTIGATION OF THE EFFECT OF FORMWORK SHAPE ON PACKING DENSITY OF AGGREGATES
}

\author{
${ }^{1}$ Kitti AJTAYNÉ KÁROLYFI", ${ }^{2}$ Dániel HARRACH, ${ }^{3}$ Ferenc PAPP \\ 1,2,3 Department of Structural and Geotechnical Engineering, Faculty of Architecture, Civil \\ Engineering and Transport Sciences, Széchenyi István University, Györ, Egyetem tér 1 \\ Hungary, e-mail: ${ }^{1}$ karolyfi.kitti@sze.hu, ${ }^{2}$ harrda@sze.hu, ${ }^{3}$ pappfe@sze.hu
}

Received 25 December 2019; accepted 30 March 2020

\begin{abstract}
Packing density of aggregate influences greatly the properties of concrete. Maximization of packing density increases the flowing ability and segregation resistance of the fresh concrete and the compressive strength of the hardened concrete. The determination of maximum density is difficult experimentally; therefore several models have been developed for that purpose. However, these models do not take the size of the formwork into account. In this study, 20 different formwork shapes were examined with defined aggregate fractions. Results show that increasing the formwork size increases the packing density of aggregate, and the growth depends on the formwork size and compaction method.
\end{abstract}

Keywords: Packing density, Aggregate, Formwork shape

\section{Introduction}

Achieving the maximum density of the aggregate is one of the most important objectives of concrete design. The higher packing density of aggregate improves the performance of both of the fresh and hardened concrete by reducing the free water content and maximizing the solids [1]. The aggregate mixture with the highest packing density also gives the best workability of fresh concrete for a given volume fraction and water-to-cement ratio. Furthermore, the dense aggregate mixture requires lower amount of cement paste to fill the voids between the particles, therefore higher compressive strength can be reached.

\footnotetext{
${ }^{*}$ Corresponding Author
} 
The determination of the packing density of granular materials is a well-researched topic in different engineering fields [2]. It originates in the classic sphere packing problem, which refers to a packing by solid balls of the same radius in order to reach the maximum density. Here the term density is the ratio of the volume of the balls to the volume of the region of space filled by these balls. After Thomas Hales [3], who proved Kepler's conjecture, it is known, that the maximum density of identical solid balls can be reached with face-centered cubic packing (Fig. 1).
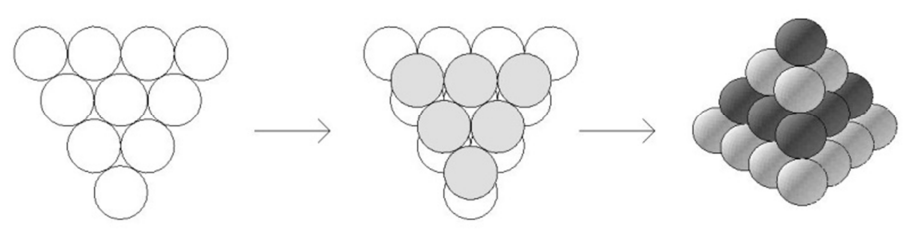

Fig. 1. Face-centered cubic packing with packing density of 0.74 , on the basis of [3]

In the case of the aggregate mixture the problem is more complicated; the packing density depends on the relative density of the particles, the particle size distribution, the particle shape, the water content of the mixture and the shape and size of the formwork as well. In this paper the authors demonstrate in what extent the size and shape of the formwork affects the packing density of different aggregate mixtures. This paper is related to a previous article published in 2018 [4], in which the authors gave an overview on the existing models for predicting the packing density and proposed hypothesizes for the present research.

\section{Packing density of granular materials}

Several methods were developed for design a dense aggregate mixture; many researchers proposed 'ideal' grading curves, which are supposed to produce the maximum packing density with proportioning the aggregate fractions properly. Although the ideal grading curves can be applied in the practice efficiently, there are many different ideal particle size distributions proposed by different authors [5]. These optimization curves are continuous particle size distributions based on geometrical considerations, and some model assumes that the change of the size scale does not affect the packing properties of the mixture. Furthermore, the particle characteristics like particle shape or packing density of the different size groups are not taken into account in these models [6]. A different approach deals with simplified aggregate fractions consisting of equal spheres. These discrete models assume that every granular class has a characteristic diameter and the packing density of a mixture with given volume fractions can be predicted based on the properties of the fractions. Nowadays, these analytical particle packing models can be applied in the practice for predicting the packing density of an entire mixture or for mixture optimization. However, these models consider only mixtures placed in a container having large dimensions, as compared with the maximum size of the aggregate [7]. Since the dimensions and shape 
of the structural elements can be considerably different, it is necessary to examine their effect on packing density of aggregate. The packing problem of solid spheres of the same radius in simple shaped formworks - for example in cubes - is already solved; increasing the side length of the cube the packing density converges to an upper limit [8], it has been also proved by experiments with aggregates as well [9]. Furthermore, there are some mathematical researches about how the geometry of the container influences the packing density of non-equal spheres [10], in concrete technology the practical application of these theories have not been introduced yet. It is still an unanswered question, how the geometrical proportions of the formwork influence the packing density of a given grain mixture.

\section{Experimental program}

The aim of this work is to examine the effect of the formwork's shape on packing density of aggregates. Four different graded aggregate fractions were used; one rounded fine aggregate fraction with a size ranging from 0-4 mm (Agg. 1) and three rounded coarse aggregate with a size ranging from 4-8 mm (Agg. 2), 8-16 mm (Agg. 3) and 16-32 mm (Agg. 4). The particle size distribution of the four fractions can be seen in Fig. 2.

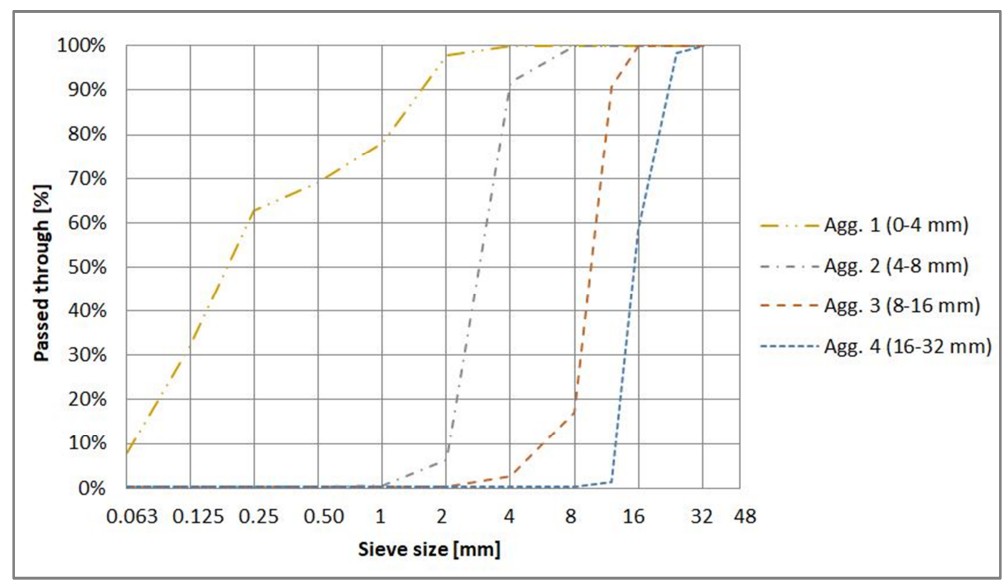

Fig. 2. Particle size distribution of the aggregate fractions

The laboratory test was divided into three parts. First, the packing density of the aggregate fractions were examined in different formworks, than the fractions were divided into components with sieving method and the packing density of the components was also examined. Finally, the limit curves ' $A$ ' and ' $C$ ' were mixed from the components and measured. The packing density of the samples can be calculated using the following equation: 


$$
\phi=\frac{\rho_{b}}{\rho_{s}}=\frac{W}{V_{c} \cdot \rho_{s}}
$$

where $\phi$ is the packing density; $\rho_{b}$ is the bulk density; $\rho_{s}$ is the specific gravity; $W$ is the weight of the aggregate and $V_{c}$ is the volume of the container. The specific gravity of the different aggregate samples is illustrated in Table $I$.

\section{Table I}

Specific gravity of the aggregate samples

\begin{tabular}{|c|c|}
\hline $\begin{array}{c}\text { Examined } \\
\text { material }\end{array}$ & $\begin{array}{c}\text { Specific } \\
\text { gravity }\left[\mathrm{kg} / \mathrm{m}^{3}\right]\end{array}$ \\
\hline Agg. 01 & 2642.28 \\
Agg. 02 & 2628.30 \\
Agg. 03 & 2625.83 \\
Agg. 04 & 2616.54 \\
0.063 & 2695.82 \\
0.125 & 2673.26 \\
0.25 & 2681,90 \\
0.5 & 2600.01 \\
1 & 2636.43 \\
2 & 2614.93 \\
4 & 2649.21 \\
\hline
\end{tabular}

Three different formworks were used in order to examine the effect of the formwork size on packing density of aggregate. In the first part of the experiment a unique formwork was used with a height and width of $60 \mathrm{~cm}$ and a moveable wall, which allows setting up a box with ten different thicknesses from 5 to $50 \mathrm{~cm}$ in steps of $5 \mathrm{~cm}$ (Fig. 3).

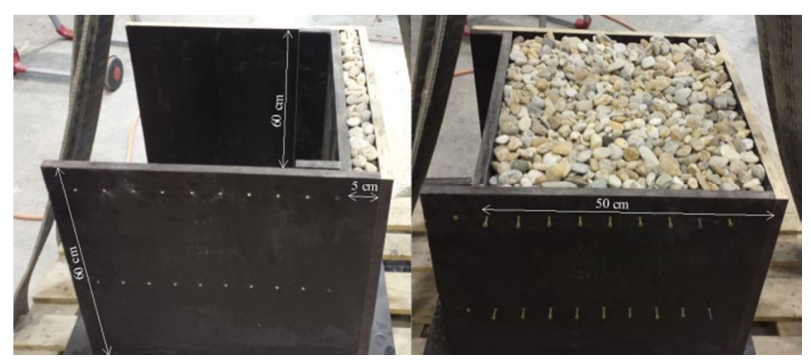

Fig. 3. First formwork used for the aggregate fractions

The second formwork was a group of six rectangular boxes with a constant height and width of $30 \mathrm{~cm}$ and thicknesses from 5 to $30 \mathrm{~cm}$ (Fig. 4).

The third formwork was a group of four cylindrical containers with a constant diameter of $7.1 \mathrm{~cm}$ and a variable height from 5.2 to $8.2 \mathrm{~cm}$ (Fig. 5).

Since the packing density also depends on the compaction method, the samples were measured in both loose and dense condition. Different compaction methods were used 
in the case of the different formworks because of the scale. The summary of the experiments is illustrated in Table II.

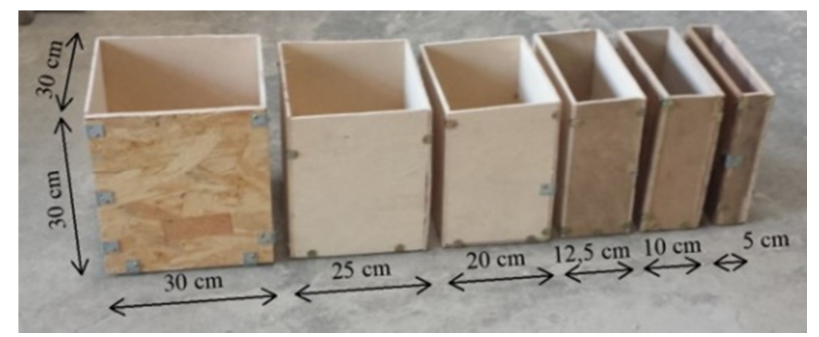

Fig. 4. Second formwork group used for the aggregate fractions and limit curves

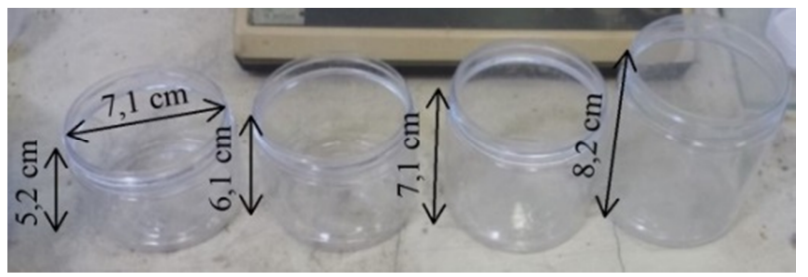

Fig. 5. Third formwork group used for the components

Table II

Summary of the experiments

\begin{tabular}{|c|c|c|c|}
\hline $\begin{array}{l}\text { Examined } \\
\text { material }\end{array}$ & Formwork size $[\mathrm{cm}]$ & Compaction method & $\begin{array}{c}\text { Number of } \\
\text { examined } \\
\text { formworks }\end{array}$ \\
\hline Agg. 01 & $\begin{array}{l}5 \times 60 \times 60-50 \times 60 \times 60 \\
5 \times 30 \times 30-30 \times 30 \times 30\end{array}$ & $\begin{array}{l}\text { Internal vibration } \\
\text { Table vibration }\end{array}$ & 16 \\
\hline Agg. 02 & $\begin{array}{l}5 \times 60 \times 60-50 \times 60 \times 60 \\
5 \times 30 \times 30-30 \times 30 \times 30\end{array}$ & $\begin{array}{c}\text { Internal vibration } \\
\text { Table vibration }\end{array}$ & 16 \\
\hline Agg. 03 & $\begin{array}{l}5 \times 60 \times 60-50 \times 60 \times 60 \\
5 \times 30 \times 30-30 \times 30 \times 30\end{array}$ & $\begin{array}{l}\text { Internal vibration } \\
\text { Table vibration }\end{array}$ & 16 \\
\hline Agg. 04 & $\begin{array}{l}5 \times 60 \times 60-50 \times 60 \times 60 \\
5 \times 30 \times 30-30 \times 30 \times 30\end{array}$ & $\begin{array}{l}\text { Internal vibration } \\
\text { Table vibration }\end{array}$ & 16 \\
\hline 'A' limit curve & $5 \times 30 \times 30-30 \times 30 \times 30$ & Table vibration & 6 \\
\hline ' $\mathrm{C}$ ' limit curve & $5 \times 30 \times 30-30 \times 30 \times 30$ & Table vibration & 6 \\
\hline 0.063 & $\mathrm{~d}=7.1 \mathrm{~h}=5.2-8.2$ & Dropping & 4 \\
\hline 0.125 & $\mathrm{~d}=7.1 \mathrm{~h}=5.2-8.2$ & Dropping & 4 \\
\hline 0.25 & $\mathrm{~d}=7.1 \mathrm{~h}=5.2-8.2$ & Dropping & 4 \\
\hline 0.5 & $\mathrm{~d}=7.1 \mathrm{~h}=5.2-8.2$ & Dropping & 4 \\
\hline 1 & $\mathrm{~d}=7.1 \mathrm{~h}=5.2-8.2$ & Dropping & 4 \\
\hline 2 & $\mathrm{~d}=7.1 \mathrm{~h}=5.2-8.2$ & Dropping & 4 \\
\hline 4 & $\mathrm{~d}=7.1 \mathrm{~h}=5.2-8.2$ & Dropping & 4 \\
\hline \multicolumn{3}{|r|}{ Total: } & 104 \\
\hline
\end{tabular}




\section{Results}

The four aggregate fractions were tested in both loose and dense conditions using the first and second formwork. The packing density values are plotted in diagrams as a function of the width of the formwork and the volume/surface ratio in Fig. 6.

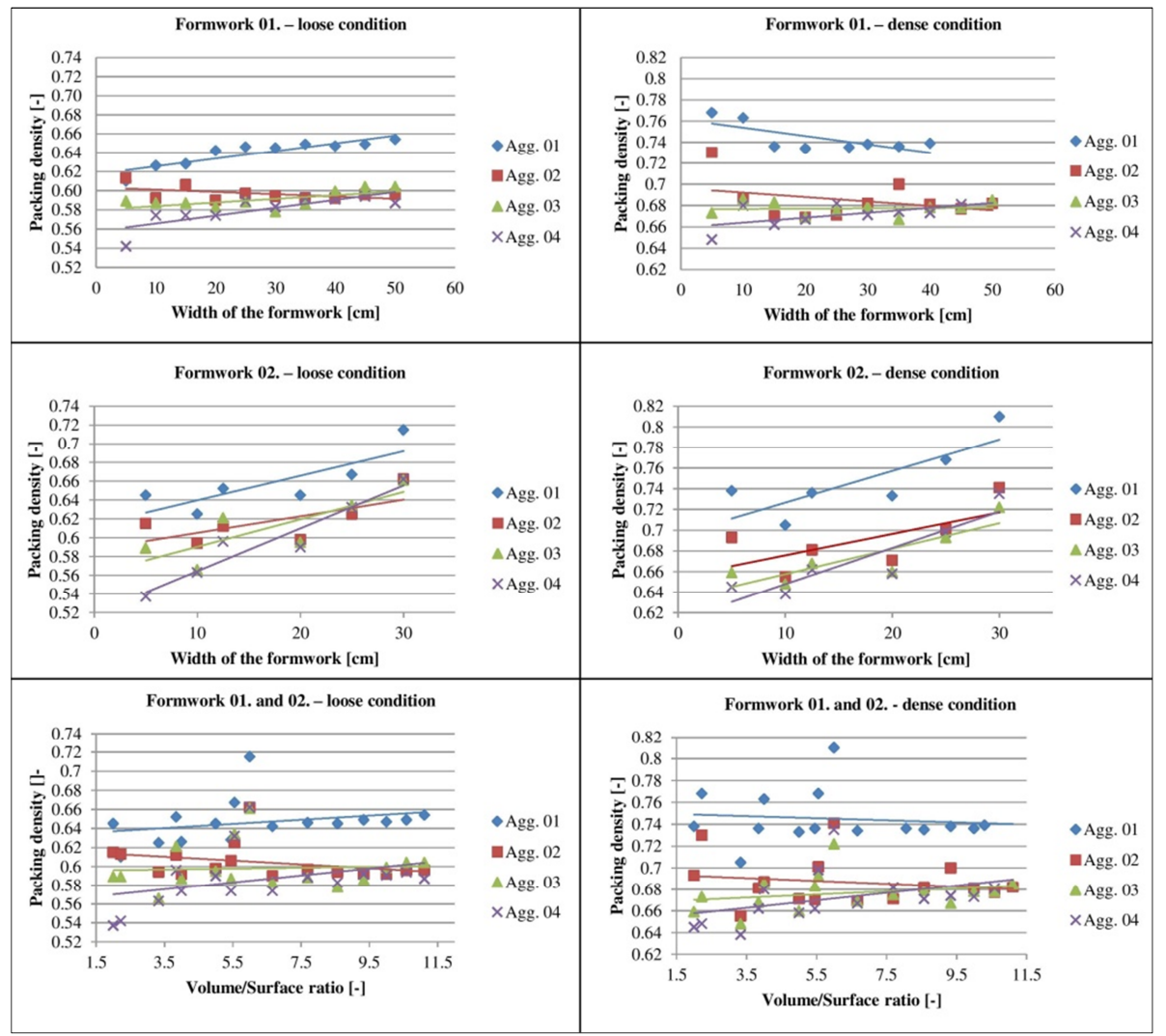

Fig. 6. Packing density of the fractions

The components were measured in the cylindrical formwork using manual compaction method. The packing density values can be seen as a function of the height of the cylinder in Fig. 7 and Fig. 8 in loose and dense condition.

The mixtures of upper and lower limit curves were tested in the second formwork. The packing density values are plotted on a diagram in Fig. 9.

There are significant correlations between the size and shape of the formwork and the packing density of aggregates. In general, the packing density is increasing with increasing width of the formwork in almost all cases. The growth is different in the case of the three formworks. The average increase of the packing density is $2-3 \%$ in loose condition and $2-4 \%$ in dense condition in case of the first formwork. The average 
increase is higher in case of the second formwork - 5-6\% in loose and 6-7\% in dense condition - which can be the result of the more efficient compaction method. The packing density is also increasing with decreasing particle size.

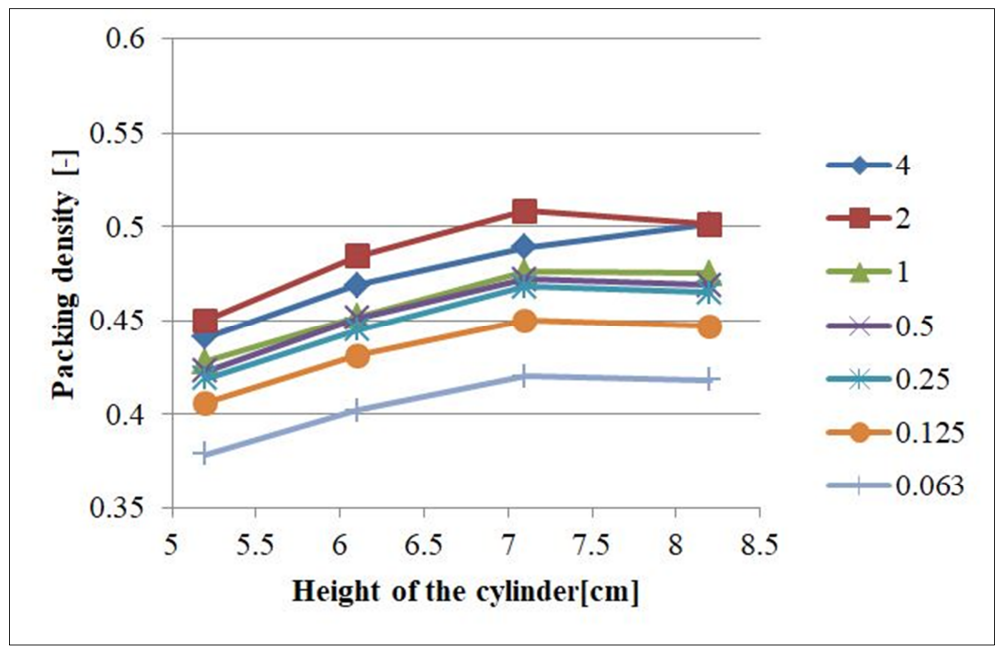

Fig. 7. Packing density of the components in loose condition

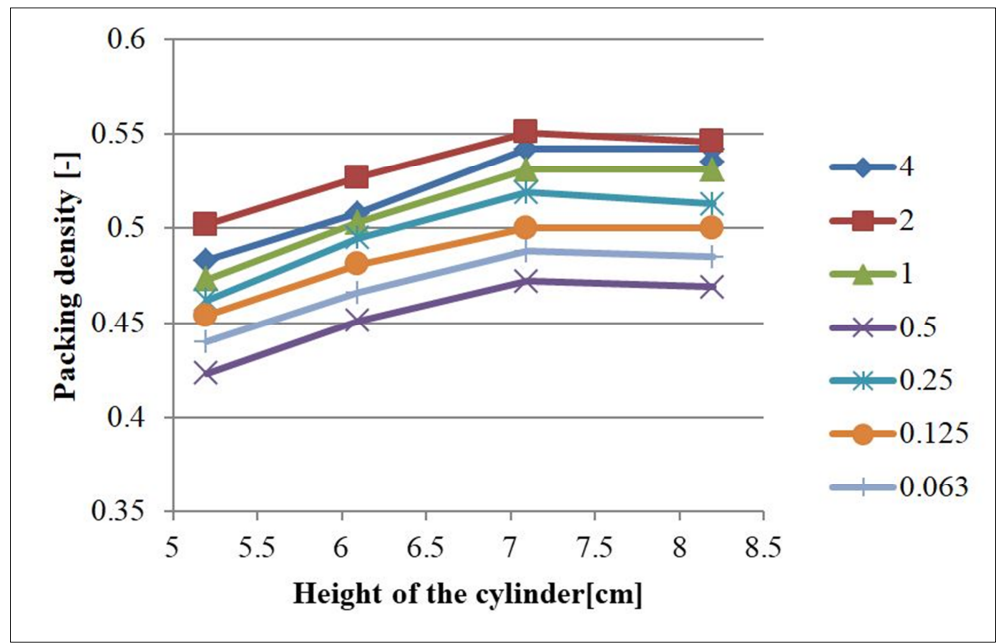

Fig. 8. Packing density of the components in dense condition

If the packing density is examined as a function of the volume/surface ratio of the formwork, it tends to a very similar value in case of the coarse fractions. The packing density of the fine fraction is higher in both loose and dense condition. Furthermore, the 
small volume/surface ratios can lead to widely differing results; the packing density reaches its maximum value at a ratio between 5.5 and 6.0 .

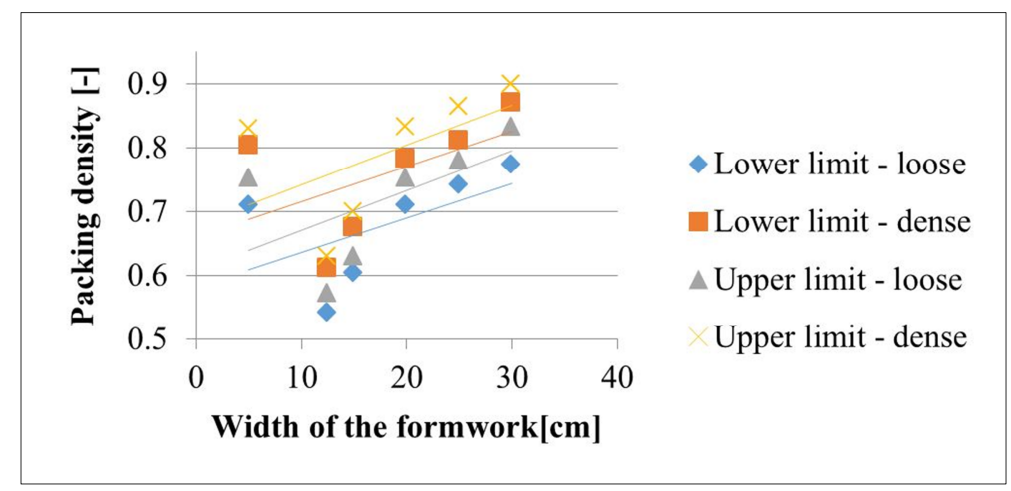

Fig. 9. Packing density of the upper and lower limit curves

In case of the components the average growth of the packing density is $4 \%$ with increasing height of the cylinder, which is in accordance with the experimental results of Lecomte [11]. Furthermore, the average packing density is lower in case of smaller particles, which is also consistent with the experimental data of De Larrard [7]. The packing densities increase with the diameter of the particles. This could be due to the fact that the compaction is more efficient in compacting coarse grains than fine ones, because the total surface area and therefore the internal friction are lower. This difference is even more significant under the particle size of $1 \mathrm{~mm}$. [7], [12] Additional differences between the packing densities of the different particle sizes in loose and dense condition could be due to the differences in the shape of the particles.

The packing density of the lower and upper limit curves have a very similar trend; it has a high initial value at the smallest width of the formwork $(5 \mathrm{~cm})$, and after a significant decrease the packing density increases gradually. The average growth is $6-7 \%$, which is higher than in the case of the fractions or the components, and the mixture of the upper limit curve reaches higher values as well. These results are in accordance with the literature data [7], [12]. The high initial packing density values can be observed in the case of the fractions as well, the reason of it has to be searched by additional tests.

\section{Summary and future scope}

This paper presents the effect of formwork size on packing density of aggregates. Four graded aggregate fractions, the components and two limit curves were examined using three different formworks in both loose and dense condition. It can be concluded that the packing density is strongly influenced by the size and shape of the formwork. The packing density is increasing with increasing volume/surface ratio of the formwork. However, the growth is more significant in case of smaller ratios, after a ratio of 6.0 , the 
packing density of the coarse fractions tends to an upper limit between 0.58 and 0.60 in loose condition and to an upper limit of 0.69 in dense condition. The packing density of the fine fractions converges to 0.65 in loose and 0.74 in dense condition above the same ratio.

In case of cylindrical formwork the packing density grows at an even rate and tends to an upper limit. It does not have any outstanding value at smaller heights of the container in contrast with the rectangular formworks. The increase of the packing density is smoother than in the case of the rectangular formwork, the reason of it can be the local decrease in packing density near the corners of the formwork.

The packing density is highly influenced by the compaction method as well; the values of the dense condition are well above the ones in loose condition. Furthermore, the different compaction methods result in different growths of the packing density.

These results lead to the conclusion that in case of slender concrete elements the achievable packing density can be considerably different than usual. The maximal packing density determinates the amount of the cement paste needed for the saturated condition, which means that the optimal concrete mixture greatly depends on the dimensions of the formwork.

The authors would like to compare these experimental data with the results of the above mentioned particle packing models. Discrete element method simulations can be also useful to be able to define the maximal packing density according to the formwork shape and size.

\section{Acknowledgements}

The research presented in this paper was carried out as part of the 'Talent Management in Autonomous Vehicle Control Technologies (EFOP-3.6.3-VEKOP-162017-00001)' project in the framework of the New Széchenyi Plan. The completion of this project is funded by the European Union and co-financed by the European Social Fund.

\section{Open Access statement}

This is an open-access article distributed under the terms of the Creative Commons Attribution 4.0 International License (https://creativecommons.org/licenses/by/4.0/), which permits unrestricted use, distribution, and reproduction in any medium, provided the original author and source are credited, a link to the $\mathrm{CC}$ License is provided, and changes - if any - are indicated. (SID_1)

\section{References}

[1] Moutassem F. Assessment of packing density models and optimizing concrete mixtures, International Journal of Civil, Mechanical and Energy Science, Vol. 2, No. 4, 2016, pp. 29-36. 
[2] Vojtech B., Pavel N. Small selection of old open packing problems, Pollack Periodica, Vol. 7, No. 1, 2012, pp. 21-28.

[3] Hales T. Cannonballs and honeycombs, Notices of the AMS, Vol. 47, No. 4, 2000, pp. 440-449.

[4] Károlyfi K., Papp F. The correspondences between formwork geometry and concrete composition in the case of fair-faced concrete elements, Pollack Periodica, Vol. 13, No. 5, 2018, pp. 43-54.

[5] Ujhelyi J. Design of the structure and compressive strength of concrete, (in Hungarian) DSc Thesis, Magyar Tudományos Akadémia, Budapest, 1989.

[6] Fennis S.A.A.M., Walraven J.C. Using particle packing technology for sustainable concrete mixture design, HERON, Vol. 57, No. 2, 2012, pp. 73-101.

[7] De Larrard F. Concrete mixture proportioning, A scientific approach, Modern concrete technology series, Vol. 9, Taylor \& Francis, e-Library, 2011.

[8] Roussel N. Understanding the rheology of concrete, Woodhead Publishing, Cambridge, 2012.

[9] Mostofinejad D., Reisi M. A new DEM-based method to predict packing density of aggregates considering their grading and shapes, Construction and Building Materials, Vol. 35, 2012, pp. 414-420.

[10] Scheithauer G., Stoyan Y., Yaskov G. Packing non-equal spheres into containers of different shapes, Dresden University of Technology, Germany, 2013.

[11] Lecomte A. The measurement of real and virtual packing density of soft grains, Materials and Structures, Vol. 39, No. 1, 2006, pp. 63-80.

[12] Alexander M., Mindess S. Aggregates in concrete, Modern concrete technology series, Vol. 13, Taylor \& Francis, e-Library, 2010. 